\title{
THE CASE OF CAPOGROSSI IN ROME: COLLECTING DATA WITH DIFFERENT TECHNOLOGIES ON A CONTEMPORARY MURAL PAINTING
}

\author{
Paola Mezzadri ${ }^{\text {a }}$, Jacopo Russo ${ }^{\text {b }}$ \\ ${ }^{a}$ Private Conservator, Via Pian di Sco 23, 00139 Rome, Italy p.mezzadri99@gmail.com \\ ${ }^{\mathrm{b}}$ Private Architect, Via dei Ginepri 11,00171 Rome, Italy j.russo@lacab.it
}

KEY WORDS: Capogrossi, Contemporary Mural Painting, Collecting Data, Technologies, Digital Stereophotogrammetry, CAD and GIS graphic documentation.

\begin{abstract}
This paper focuses on the presentation of a part of the main thematic data documenting the pathologies and the degradation problems of a contemporary mural painting, which was designed and carried out by the italian artist Giuseppe Capogrossi in 1954. This forgotten masterpiece is developed on the ceilings of the main double stairscase at the entrance of the Airone, an ex-cinema-theatre in Rome (Italy). In time, the original project was completely damaged and now the Airone cinema is abandoned since 1999; the decoration, strictly connected to the function of the original project, has been completely covered by synthetic coatings. The documentation of the observed pathologies and the original materials of the lower ceiling takes place during a restoration project in 2015-2016 and was accomplished by utilizing different technologies in order to facilitate the collecting of the main data within several graphic thematic tables. The challenge of this documentation was to create a contact point, and perhaps also a contamination, between the practices of CAD graphic documentation, restoration and GIS technology.
\end{abstract}

\section{THE CAPOGROSSI WALL PAINTING AT THE AIRONE EX CINEMA-THEATRE}

\subsection{Introduction: conservation history}

The wall painting is developed on the ceilings of the main double stairscase at the entrance of the Airone, an ex-cinematheatre in Rome which is situated seven meters below the street level and thus, in a conservation way, can be associated to the typology of the hypogeum. The building, located inside a central court enclosed by five blocks of flats, was commissioned by a public corporation and was designed and planned during the Fifties by the famous architects Adalberto Libera, Eugenio Montuori and by the engineer Leo Calini (Calandra 1956, Zevi 1956, Aloi 1958, Montuori 1981, Garofalo and Veresane 1989, Bonavita 2003, Pellicano 2007). During that period, Capogrossi had already matured a visual vocabulary of irregular comb or fork-shaped signs (Bolpagni, 2013).

This particular painting was developed on the basis of the architects' plans, even though it could be linked to the Informal artistic movement. As observed during the restoration project, and as the old surveyor of the time described, the abstract geometric style of the painting - which is made of a graphic and modular repetition of brilliant and "pop"colours - was connected together by utilizing modular elements onto the walls. Overall, in line with the architectural plan, the painting recalls the imagery of a large crowd flowing inside the cinema, their countless eyes watching around. In time, the Airone cinema lost its identity and became in order: a ballroom, a nightclub, a discotheque and eventually a strip club.

The original project was twisted, transformed and damaged and the decoration - strictly connected to its function - has been completely covered by synthetic coatings first due to the water ingress and then due to the changing use of the building for different purposes; nine layers (De Cesare et al. 2015) developed over the upper ceiling of the double staircase and six over the lower ceiling (Mezzadri and Gaetani 2016). The building is abandoned since 1999 and the documentation of all the conservative problems of the lower ceiling was carried out in 2015-2016 during a conservation project where a sample area was instead completely restored (Mezzadri 2015).

\subsection{Conservation pathologies}

The painting had a complex conservation history which needed to be clearly designed in order to facilitate the comprehension of all the pathologies observed. In fact, all the water ingress focused on the lower ceiling had caused the main degradation problem activating a contraction process in most of all the six overpainted layers; this process was characterized by the softening of the layers at first, followed by water evaporation with a consequential contraction. Also the loss of materials like additives and surfactants (due to the water flow) increased this contraction with the substantial rip and delamination of the original film beneath.

Other degradation causes like lacunae, swelling, mixing and loss of cohesion of the original colors - the latter especially connected to the high presence of efflorescence and subflorescence of soluble salts - were all due to the persistency of the water through the painting. Therefore, the graphic documentation was fundamental to develop a correct approach to manage, show and impart knowledge about all the degradation problems described above.

\subsection{The survey phase: choices behind the realization of a digital stereophotogrammetry}

The photographic survey phase and the CAD graphic documentation were carried out over all the lower ceiling of the painting, the one most damaged; its area, as reported by CAD, was $31,45 \mathrm{~m}^{2}$. The first step was to create a unique photographic base of the ceiling (an orthophoto) in order to collect data for the conservation project. The accomplished technology was the digital stereophotogrammetry, even though applied on a twodimensional surface such as a wall painting. This choice was conditioned by many factors such as the geometrical space of the double staircase in which was situated the painting. In fact, it was not possible to obtain a high-quality picture of the ceiling with a single photographic shot due to the nearness between the 
steps of the staircase and the inclined intrados of the attic (composed by concrete and bricks). Moreover, the particular degradation process of the synthetic overpainted layers, due to the water ingress, was also characterized by massive deformations and partial detachments of the latter. Depending on the angle of the photographic framing, some hanging portions of the overpainted layers were generating shaded and hidden areas of the lower ceiling. This visual inhomogeneous situation prevented to measure the correct distance between the targets that had to be applied to the surface in order to create the photographic base; for all these reasons a two-dimensional object such as a wall painting was instead characterized by three dimensions. Therefore, the best method to reproduce the lower ceiling was to create a textured tridimensional model of the painting highlighting eventually also its structural pathologies. The digital stereophotogrammetry allowed to reconstruct the geometry of the wall painting like a three-dimensional object by generating a cloud of high-density points (dense cloud); each of these points was reconstructed from at least two photographs taken from different positions in which the point was visible. The photos were all acquired in RAW file and then were automatically linked and aligned together by the digital software Agisoft Photoscan that compared homologous points (pixel sequences that represent the same details) in the different frames. Once executed the alignment of all the photographs, the dense cloud was generated and was then interpolated by the software to obtain a dense network of triangles called mesh. Finally, the photographic texture - obtained starting from the same photos used to generate the dense cloud - was re-projected on the mesh; from this three dimensional textured model, projecting it on an imaginary plane with parallel beams between them, it was possible to obtain the orthographic image of the lower ceiling (fig.1).



Figure 1. Orthophoto of the lower ceiling of the Capogrossi wall painting at the Airone cinema. Image: Paola Mezzadri all rights reserved.

The first problem which had to be practically solve in situ was the presence of mirrors on the vertical walls of the staircase; in fact, in order to avoid the specular reflections than can cause errors in the stereophotogrammetry data processing, they were previously covered with sheets of paper. Since approximately $3 / 4$ of the surface was completely covered by the last blue-gray overpainted layer, which was very compact, small masking tape portions were previously applied above it in order to avoid any problems focusing while shooting. The tape was applied also due to the chromatic homogeneity of the layer in order to 
facilitate the alignment of the photos by the software Agisoft Photoscan; the alignment was easy thanks to the deformations of the surface, anyway.

An imaginary plane on which to perform the projection was identified by affixing three targets on the vertical walls, $70 \mathrm{~cm}$ below the ceiling. In this way it was built an imaginary parallel plane to the one of the ceiling shifted downwards of $70 \mathrm{~cm}$, sufficient to accomplish the measurements without encountering obstacles constituted by the hanging portions of the overpainted layers. The position of the targets was determined downwards with a pendulum laser level.

The photographic shots were realized with the easel and with different exposures (fixed and variable time diaphragm) ensuring a correct exposure time in each area. All the photographic images were obtained by utilizing four halogen lamps, two placed at the landing between the double stairscase and two at the bottom; the lamps were directed against reflector panels in order to illuminate the wall painting in the most homogeneous manner. Each stairway had 16 steps and was divided into three parts by two handrail columns. Therefore, 9 photos were performed for each step reaching a total of 144 photos to obtain the final whole orthophoto of the lower ceiling. All the 144 photos were acquired in RAW file and subsequently saved in TIFF format. Radial image distortion and spherical aberration were corrected (with Photoshop) during this stage; after that, all the photos were linked and aligned together obtaining a textured three-dimensional model and an orthographic image with a resolution of $0,5 \mathrm{~mm}$ per pixel.

The photographic survey phase was repeated at the end of the restoration project in the same way described above obtaining a second georeferenced orthophoto, not shown in this paper, in order to appreciate all the conservation improvements in the painting. Thanks to these two orthophotos it was possible to perform a very detailed graphic documentation and, since both of them were perfectly superimposable, it was possible to compare in time the variation of all the pathologies observed.

\subsection{The graphic documentation: collecting data about pathologies and materials with CAD and GIS}

These high quality images allowed to document precisely all the previous interventions on the painting, such as the six layers overpainted, within a thematic graphic table by utilizing CAD software (fig.2).
The table shows the overpainted layer n.6 (grey-blue colour) and n.2 (green colour) that were visible; the other layers were anyway present but hidden from the latter. Moreover, due to the persistency of the water ingress during the first part of the restoration project ( $\mathrm{RH} 80-90 \%$ and $\mathrm{T}$ that was following the external fluctuations), another thematic graphic table of the overpainted layers, not reported in this paper, was accomplished. This table shows how some portions of the four overpainted layers were removed as a preventive and conservative operation in order to facilitate the evaporation process after the re-roofing by the construction company in charge; the table, based on the second and final georeferenced orthophoto, was necessary to cross all the data collected in CAD and to facilitate GIS documentation.

The complicated state of conservation was instead divided in three graphic thematic tables: A, B, C (respectively figg.3, 4, 5). This choice was necessary in order to draw a proper documentation with CAD avoiding the overlapping of different pathologies perimeters and to clearly represent all the degradation problems.

One interesting observation, which was reported in the state of conservation (table $\mathrm{C}$ ), was the atypical degradation of the linear original elements of the painting due to the water ingress; their different medium swelled quickly creating a lots of efflorescence and/or subflorescence readable even underneath the overpainted layers (see fig. 5). This was really useful to locate the original linear signs, even though they were hidden by the overpainted layers, and to understand the water ingress areas.

However, the major problem of this documentation was to draw with $\mathrm{CAD}$ all these massive perimeters and to manage them; moreover, some areas of the overpainted layers were often fragmented into pieces (especially the green layer n.2). Therefore the GIS technology was used like an aid of CAD to create "in negative" other polygonal areas like the one of " abrasion and micro-lacunae of the original film"; in fact, the latter was created by the GIS software subtraction of the bluegrey overpainted layer CAD perimeter with the green one (see brilliant green areas in fig. 4). In this way, it was possible to accelerate the documenting process collecting data in order to obtain precise areas where conservative measures need to be applied and calculate the cost of all the future conservative operations for the final restoration project. 
The International Archives of the Photogrammetry, Remote Sensing and Spatial Information Sciences, Volume XLII-5/W1, 2017 GEOMATICS \& RESTORATION - Conservation of Cultural Heritage in the Digital Era, 22-24 May 2017, Florence, Italy

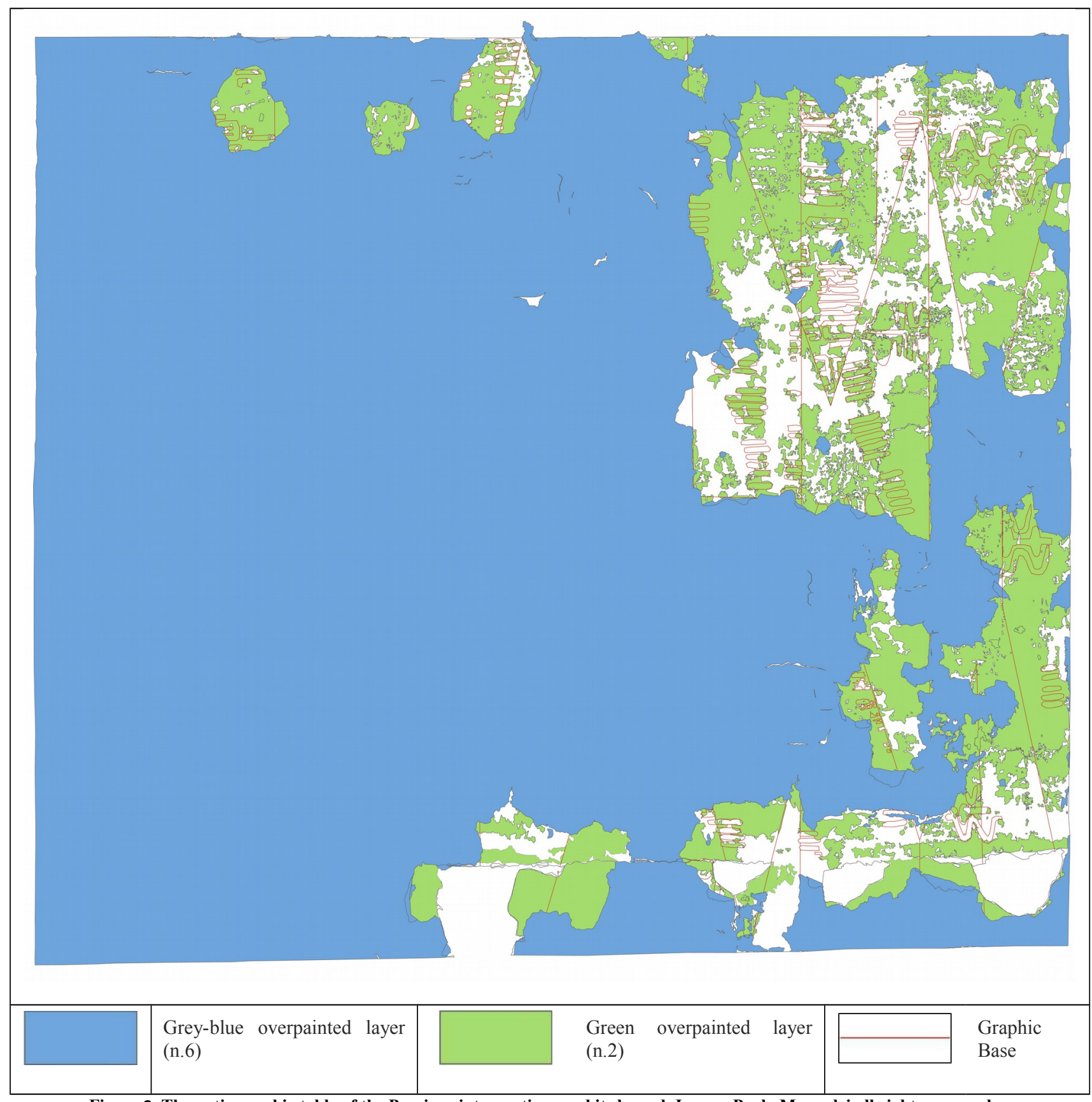

Figure 2. Thematic graphic table of the Previous interventions and its legend. Image: Paola Mezzadri all rights reserved. 


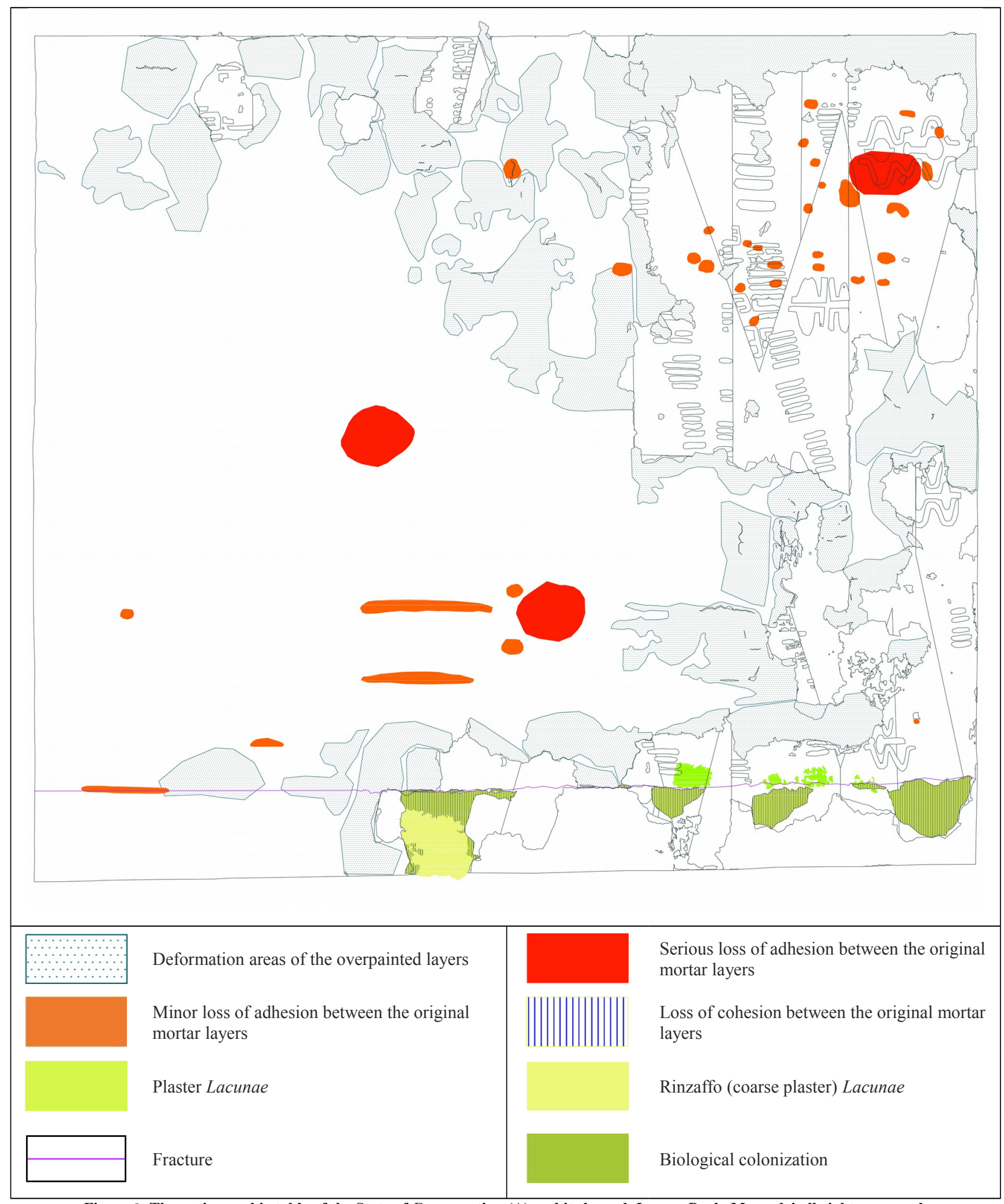

Figure 3. Thematic graphic table of the State of Conservation (A) and its legend. Image: Paola Mezzadri all rights reserved. 


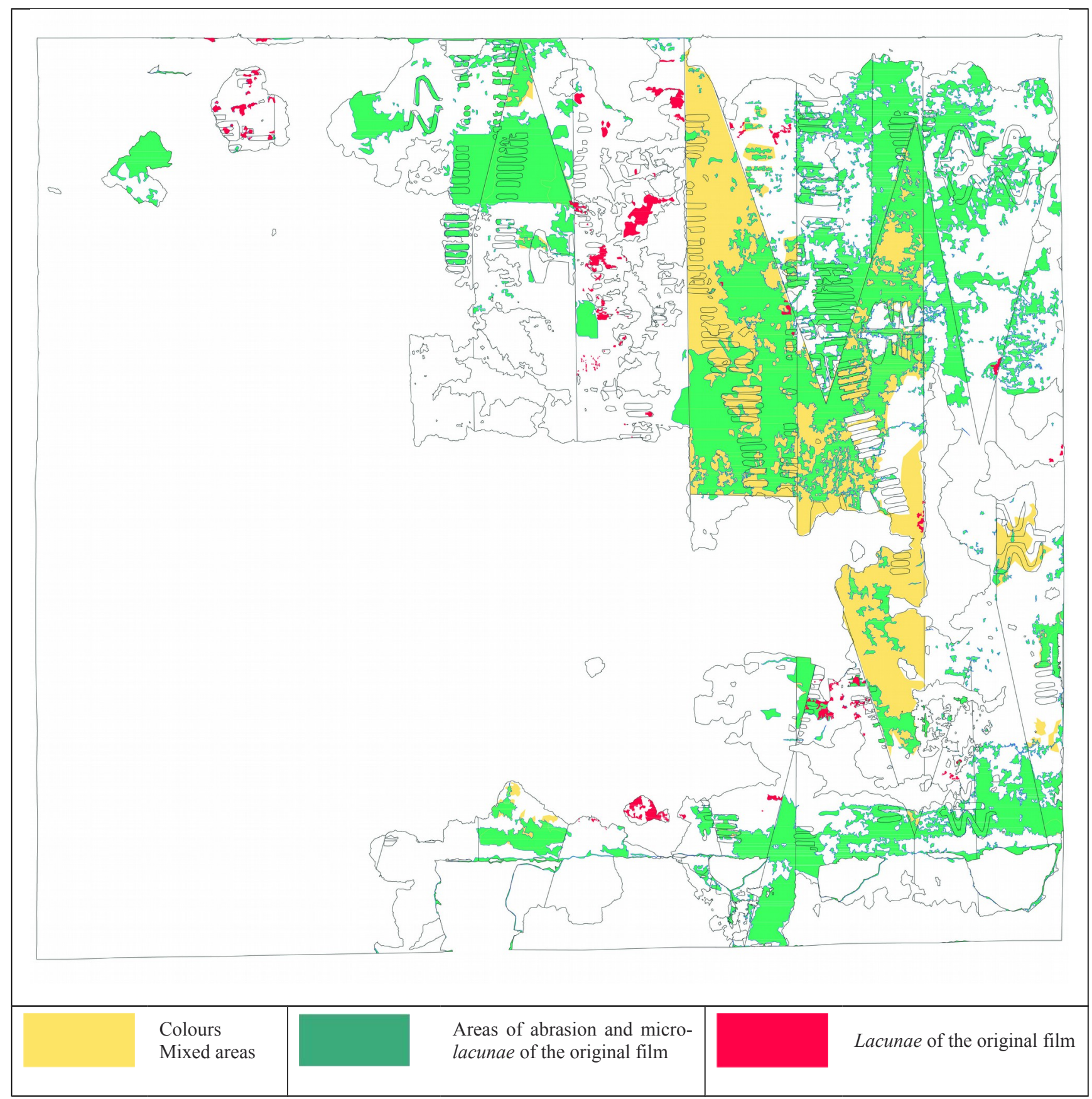

Figure 4. Thematic graphic table of the State of Conservation (B) and its legend. Image: Paola Mezzadri all rights reserved. 


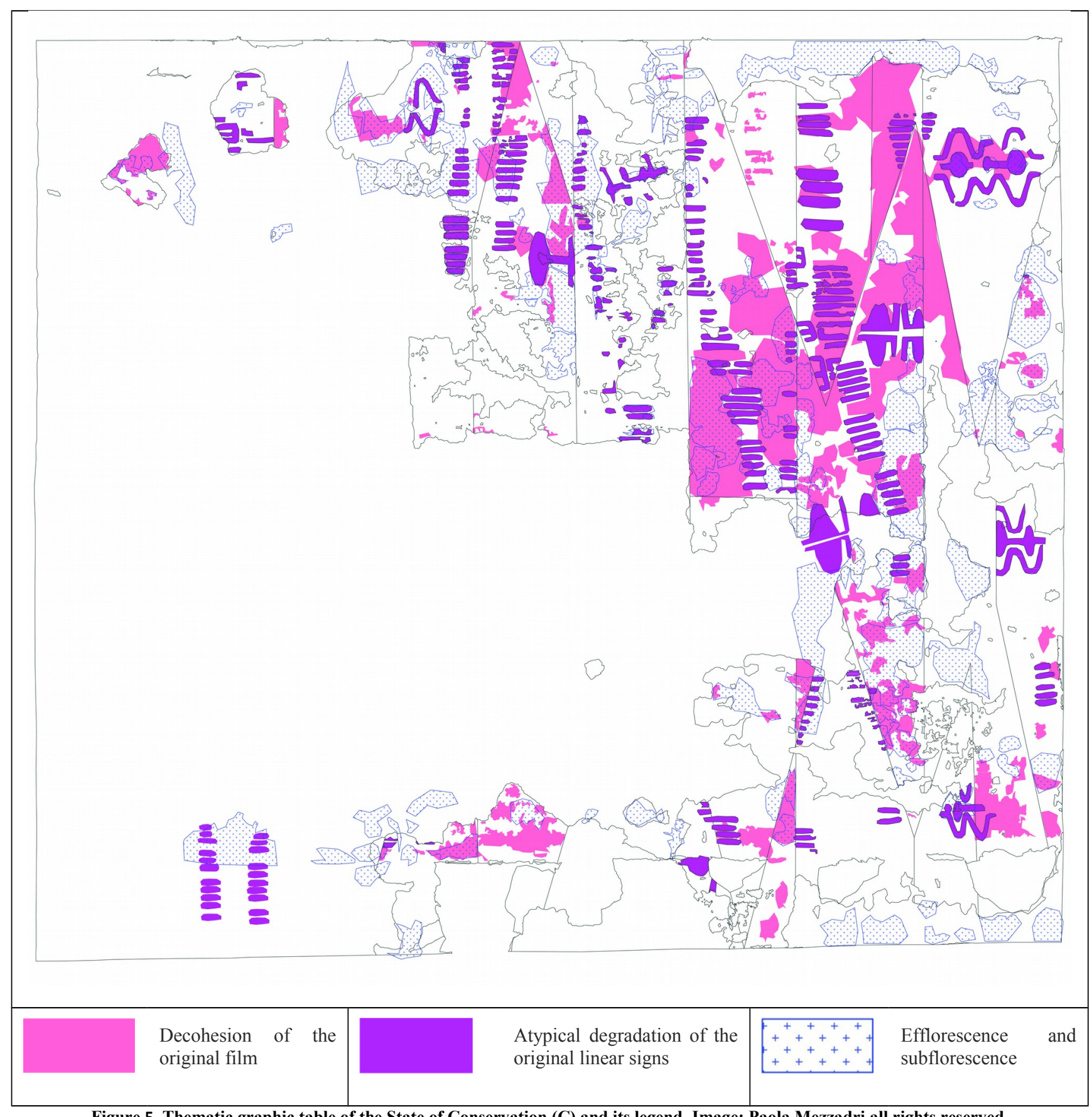

Figure 5. Thematic graphic table of the State of Conservation (C) and its legend. Image: Paola Mezzadri all rights reserved. 


\subsection{Conclusions}

The challenge of this documentation was to create a contact point, and perhaps also a contamination, between the practices of CAD graphic documentation, restoration and GIS. In fact, during the conservation project, these disciplines had resulted consecutive steps because the perimetral areas of the overpainted layers - which hid the original one - were often divided and fragmented into pieces; therefore, the use of the GIS technology - as an aid of the CAD documentation - allowed to elaborate faster some of these polygonal areas promoting the creation of others "in negative" and accelerating the working process. The application and the support of the GIS technology, generally used in documentation of monumental complexes, allowed to manage better the massive collection of data observed during the photographic survey phase and during the restoration project too allowing to calculate the costs of the latter. That is probably one of the main point achieved during the process of documentation of the Capogrossi wall painting at the Airone ex-cinema.

\section{Acknowledgement}

This conservation project was carried out by conservator Paola Mezzadri as her final dissertation for the Istituto Superiore per la Conservazione e il Restauro (ISCR), Rome, Italy, which was submitted in April 2016. The intellectual contribution and support of all the multi-disciplinary ISCR team was crucial for both elucidating the issues and decisions making for treatment. The ISCR team included: Maria Carolina Gaetani, conservator; Laura D'Agostino, Art historian; Giancarlo Sidoti, Lucia Conti and Luigi Arceri, chemists; Marco Bartolini, biologist; Carlo Cacace and Fabio Aramini, physicists; Jacopo Russo, architect, for graphic and photographic documentation; and Annamaria Pandolfi, architect. For permission to examine and treat the wall painting, we are extremely grateful to Morena Costantini, art historian and ministerial authority for the Soprintendenza archeologia belle arti e paesaggio for the municipality of Rome; and Silvia Corsi, architect for the U.O. Città Storica di Roma and designer of the project Requalification of the Airone Cinema-Theatre. I would also like to extend my gratitude to Gugliemo Capogrossi, Francesco Montuori and the late Giunio Tabacchi for their invaluable help.

\section{References}

Aloi, R. 1958. Architetture per lo Spettacolo, Milano: Hoepli, p. 354 et seq.

Bolpagni, P. 2013. 'Capogrossi e una "idea” di Italian Style', in M.L. Barbero (ed.), Capogrossi. Una retrospettiva, Venezia: Marsilio, p. 344.

Bonavita, A. 2003. 'Cinema Airone', scheda C.23, in G. Remiddi and A. Greco (eds), Adalberto Libera. Guida a 45 architetture, Rome: Palombi.

Calandra, M. 1956. 'Cinema Airone a Roma', L'Architettura. Cronache e Storia, 1(5): 662-667.

De Cesare, G., Gurgone, N., Putaturo, G., Miliani C. and Rosi F., 2015. 'Murals And Architecture: The Case Of Capogrossi in
Rome', pp. 133-142, in M. Sánchez Pons, W. Shank and L. Fuster Lopez (eds), Conservation Issues in Modern and Contemporary Murals Cambridge Scholars publishing.

Garofalo, F. and Veresane, L. 1989. Adalberto Libera, Bologna: Zanichelli, p. 159.

Mezzadri, P. 2015. Il dipinto murale di Giuseppe Capogrossi nell'ex cinema Airone: problemi conservativi e intervento di restauro, unpublished final dissertation, Conservazione e Restauro dei Beni Culturali, ISCR, Rome.

Mezzadri P. and Gaetani, M.C. 2016. 'Il dipinto murale di Giuseppe Capogrossi nell'ex cinema Airone: pronto intervento' in Lo Stato dell'Arte 14, Firenze: Nardini and IGIIC editors, pp. 265-277.

Montuori, E. 1981. Eugenio Montuori architetto, Milan: Over, pp. 56-57.

Pellicano, E. 2007. Cinema Airone, Adalberto Libera. Rilievo, recupero funzionale e riuso, in Carunchio, T., Sparvieri, R. and Volterra, S. (eds), Progetti di restauro architettonico e dei monumenti: ricerca, sperimentazione, didattica, 1: 299, 349355.

Zevi, B. 1956. 'Critica d'arte e umanità architettonica', p. 657, L'Architettura. Cronache e Storia, 1(5): 657. 